\title{
Thresholds for Synaptic Activation of Transcription Factors in Hippocampus: Correlation with Long-term Enhancement
}

\author{
Paul F. Worley, ${ }^{1,2}$ Ratan V. Bhat, ${ }^{1}$ Jay M. Baraban, ${ }^{1,3}$ Cynthia A. Erickson, ${ }^{4,7}$ Bruce L. McNaughton, ${ }^{4,6,7}$ and Carol \\ A. Barnes ${ }^{4,5,7}$ \\ Departments of ${ }^{1}$ Neuroscience, ${ }^{2}$ Neurology, and ${ }^{3 P}$ sychiatry and Behavioral Sciences, Johns Hopkins University School of \\ Medicine, Baltimore, Maryland 21205-2185 and Departments of ${ }^{4}$ Psychology, ${ }^{5}$ Neurology, and ${ }^{6}$ Physiology, and ${ }^{7}$ Division \\ of Neural Systems, Memory, and Aging, The University of Arizona, Tucson, Arizona 84724
}

Recent studies suggest a role for rapid induction of transcription factors in stimulus-induced neuronal plasticity in the mammalian brain. Synaptic activation of transcription factors has been analyzed in the hippocampus using the long-term potentiation or enhancement (LTP/LTE) paradigm. Using this approach, several studies have identified transcription factors that are induced in hippocampal granule cells by NMDA receptor-dependent mechanisms; however, the link between long-term plasticity and activation of these genes has been called into question by reports suggesting that the thresholds for LTE and gene activation differ.

To address this issue, we have used a chronic in vivo recording technique to monitor mRNA responses of several transcription factor genes to two different patterns of LTEinducing electrical stimulation of entorhinal cortical afferents to hippocampus. One pattern consisted of 10 repetitions of a 20 or 25 msec train of pulses at $400 \mathrm{~Hz}$ (80 or 100 pulses total). This "10-train" pattern has been used in previous studies of LTE and produces robust synaptic enhancement lasting at least $3 \mathrm{~d}$ (Barnes, 1979). The other stimulation pattern consisted of 50 repetitions of a $20 \mathrm{msec}$ train delivered at $400 \mathrm{~Hz}$ (400 pulses total), which is similar to parameters used in other studies reporting induction of c-fos in association with LTE (Dragunow et al., 1989; Jeffery et al., 1990; Abraham et al., 1992). Our results indicate that expression of zif 268 , monitored by in situ hybridization and immunostaining, is strongly induced by the 10-train stimulus pattern to levels similar to those induced by seizure activity. JunB mRNA levels are also modestly increased by the 10train stimulus pattern; however, increases in JunB immunostaining were not detected. Neither c-fos nor c-jun mRNA were detectably induced by this stimulus. In contrast, the 50-train stimulus pattern resulted in a robust induction of c-fos and c-jun mRNA, in addition to zif 268 and junB. Transcription factor responses to either stimulus pattern were

Received Feb. 8, 1993; revised May 3, 1993; accepted May 11, 1993.

We thank G. S. Stevenson and G. Rao for technical assistance with portions of the electrophysiological and behavioral procedures. We also thank Drs. Barbara Christy and Yusaku Nakabeppu for supplying antisera for zif 268 and jun B and Kanato Yamagata, Andrew Cole, and Anthony Lanahan for technical assistance. This work was supported by Grants AG09219, EY08900, and MH00897, the Office of Naval Research, the W. M. Keck Foundation, and the Krieger Mind Brain Institute.

Correspondence should be addressed to Dr. Paul F. Worley, Johns Hopkins University School of Medicine, Department of Neuroscience, 907 Hunterian Building, 725 North Wolfe Street, Baltimore, MD 21205-2185.

Copyright (C) 1993 Society for Neuroscience $0270-6474 / 93 / 134776-11 \$ 05.00 / 0$ blocked by the noncompetitive NMDA receptor antagonist MK-801. Identical transcription factor responses were observed in adult (6-12-month-old) and aged (23-26-monthold) rats, suggesting that synaptic mechanisms involved in these responses are preserved in aged animals. Analysis of LTE following either the $\mathbf{1 0}$ - or $\mathbf{5 0}$-train stimulus patterns revealed identical magnitudes of initial induction and decay kinetics ( $\sim 3 \mathrm{~d})$ and indicates that the 10-train stimulus pattern is sufficient to produce maximal synaptic enhancement. These studies define distinct thresholds for NMDA-dependent induction of transcription factors in hippocampus and indicate that, of the transcription factor genes examined, only the threshold for activation of zif 268 is similar to that for LTE.

[Key words: NMDA receptor, immediate-early genes, longterm potentiation, $c$-fos, zif 268, Krox20, nur77, junB, $c$-jun, fos $B]$

Classical studies of learning and memory indicate a role for rapid RNA and protein synthesis in long-term maintenance of plasticity (Agranoff, 1981). The observation that neurotransmitters induce rapid increases in expression of genes coding for proteins that bind DNA and regulate transcription (Greenberg and Ziff, 1984; Greenberg et al., 1986; Morgan et al., 1987) provided insight into mechanisms that might underlie forms of plasticity that are dependent on macromolecule synthesis. The emerging concept is that neurotransmitters may induce a regulated and sequential activation of specific genes that ultimately define the long-term cellular response (Goelet et al., 1986; Deadwyler et al., 1987; Sheng and Greenberg, 1990; Lau and Nathans, 1991).

Direct evidence of a role for regulated gene activation in plasticity was provided by Kandel and associates, who demonstrated that injection of a DNA fragment that presumably binds to and blocks activity of the transcription factor CREB inhibits longterm plastic responses in cultured Aplysia neurons (Dash et al., 1990). Studies in whole-animal, vertebrate models of plasticity have focused on correlations between gene responses to specific stimuli and subsequent long-term adaptive changes. This approach has identified a variety of physiological or artificial stimuli, many of which are known to result in long-term adaptive changes, that induce expression of specific transcription factors. For example, transcription factors c-fos and zif 268 (Christy et al., 1988; also termed NGFI-A, Egr-1, Krox 24) are induced in spinal cord neurons by peripheral nerve stimulation (Hunt et al., 1987; Bullitt, 1989; Wisden et al., 1990), in the suprachiasmatic nucleus by a photic stimulus (Aronin et al., 1990; Rusak 
et al., 1990), and in rodent somatosensory cortex by stimulating whiskers (Mack and Mack, 1992). Moreover, zif268 is induced in discrete regions of the bird forebrain in response to species specific song (Mello et al., 1992). An important result of this work is that it has defined the sensitivity of the neuronal genomic response to afferent stimuli and has implicated transcription factors in many physiological responses.

Insights into basic synaptic mechanisms regulating transcription factor expression in vivo have emerged from studies using the long-term potentiation or enhancement (LTP/LTE) paradigm in the hippocampus (Douglas et al., 1988; Cole et al., 1989; Dragunow et al., 1989; Jeffrey et al., 1990; Wisden et al., 1990; Schreiber et al., 1991; Abraham et al., 1992). A strength of this paradigm is that it permits direct assessment of the effects of electrical activity on synaptic efficacy (Bliss and Lomo, 1973; Douglas and Goddard, 1975). Additionally, the stimulus intensity threshold (McNaughton et al., 1978; Douglas et al., 1982) and transmitter pharmacology (Collingridge et al., 1984; Abraham and Mason, 1988; Reed and Robinson, 1991) for induction of long-term plasticity are well defined.

Transcription factor mRNA is rapidly induced by high-frequency synaptic stimuli that also induce LTE (Cole et al., 1989; Dragunow et al., 1989; Wisden et al., 1990). Transcription factors that are reported to be induced with LTE include zif268, jun B, c-fos, junD, and c-jun (Cole et al., 1989; Jeffery et al., 1990; Wisden et al., 1990; Abraham et al., 1992). To define further the association between LTE and transcription factor induction, investigators have examined gene responses under conditions that block or modify LIE induction. Both the transcription factor response and LTE are blocked by NMDA-type glutamate receptor antagonists (Colc ct al., 1989; Wisden ct al., 1990) and by intrinsic inhibitory pathways (Cole et al., 1989). Additionally, the threshold stimulus intensity for induction of LTE is similar to that for induction of zif 268 (Cole et al., 1989) and the decay time of LTE and degree of zif 268 induction have been found to be significantly correlated (Richardson et al., 1992).

By contrast, other reports are less supportive of an association between LTE and rapid gene responses. Studies examining the effect of different temporal patterns of synaptic stimuli suggested a negative correlation between LTE and transcription factor induction (Schreiber et al., 1991). Moreover, reports disagree on the inducibility of specific transcription factors with LTE (Dragunow et al., 1989; Wisden et al., 1990). The recent observation that general anesthesia produces a dramatic reduction in transcription factor responses may explain many of these discrepancies (Douglas et al., 1988; Dragunow et al., 1989; Jeffery et al., 1990; Abraham et al., 1992; Krukoffet al., 1992) and indicates that general anesthetics should be avoided in studies of transcription factor regulation in normal physiology. Another consideration in interpreting results using the LTE paradigm is that acute brain injury, for example, due to passing a probe through the cortex or hippocampus, causes a rapid, NMDAdependent induction of transcription factors (Dragunow et al., 1990; Cole et al., in press) that may be difficult to control in acute LTE preparations. Possible effects due to anesthetics or acute injury may be negated using a chronically implanted preparation, in which LTE stimuli are administered in awake, behaving animals long after recovery. Studies using the chronic preparation report that several transcription factors, including zif 268, c-fos, jun B, and c-jun, are induced in association with LTE (Jeffery et al., 1990; Abraham et al., 1992).
Despite these advances, several areas of uncertainty remain. Stimulus parameters typically used to induce transcription factors are more intense than are required to produce long-lasting synaptic enhancement. For example, a 50-train stimulus pattern has been used to induce c-fos in unanesthetized rats (Dragunow et al., 1989) whereas 10 trains are sufficient to induce LTE lasting 3-5 d (Barnes, 1979). This suggests a possible dissociation between the conditions sufficient for LTE induction and those necessary for induction of c-fos. Accordingly, it is important to establish the stimulus intensity necessary to induce each of these transcription factors, and to relate this to the LTE response in unanesthetized animals. The present experiments were conducted to address these issues. An additional purpose of these studies was to compare the efficiency of transcription factor activation in young and aged rats. Previous studies have demonstrated that the induction of LTE is comparable in young and old rats, whereas the rate of decay of the enhanced synaptic response is accelerated in the aged animals (Barnes, 1979; Barnes and McNaughton, 1980, 1985; de Toledo Morrell and Morrell, 1985).

Abstracts describing some of the results have been published (Barnes et al., 1991; Worley et al., 1992).

\section{Materials and Methods}

Subjects. A total of 115 Fisher 344 rats were used in the experiments described here. All rats were male retired breeders obtained from the National Institute on Aging's colony at Charles River at either 9 months $(n=97)$ or 24 months $(n=8)$ of age. All of the old rats and 61 of the young rats were implanted bilaterally with stimulating and recording electrodes (as described below). Thirty-six other rats were used as either naive controls or seizure controls [intraperitoneal injection of $50 \mathrm{mg}$ / $\mathrm{kg}$ pentylenetetrazol, or maximal electroconvulsive shock (MECS) (Cole et al., 1990)] for the in situ hybridization comparisons. Rats were housed individually, fed ad libitum, and maintained on a $12 \mathrm{hr}: 12 \mathrm{hr}$ light:dark cycle, with all recordings obtained during the dark phase of the cycle.

Surgical procedures. Surgery was performed according to NIH guidelines for rodents. Briefly, rats underwent bilateral electrode implantation under sodium pentobarbital (Nembutal, $33 \mathrm{mg} / \mathrm{kg}$ ), which was supplemented as necessary with Metofane. Recording and stimulating electrodes were constructed of $114 \mu \mathrm{m}$ Teflon-coated stainless steel wire (Medwire Corp.). The difference between the two electrodes was that $300 \mu \mathrm{m}$ of insulation was removed from the tips of the monopolar stimulating electrodes, while the insulation on the recording electrodes was intact to the tip. The coordinates used for recording and stimulation placements were $3.8 \mathrm{~mm}$ posterior to bregma and $2.0 \mathrm{~mm}$ lateral to the midline, and $8.1 \mathrm{~mm}$ posterior to bregma and $4.4 \mathrm{~mm}$ lateral to the midline, respectively (Paxinos and Watson, 1986). Final depths were adjusted under electrophysiological control to produce the maximal positive-going field response in the fascia dentata (see Fig. 1 for waveform examples). All rats were given children's Tylenol for analgesic purposes and fresh fruit for $3 \mathrm{~d}$ after surgery. One to three weeks recovery time was allowed before recording experiments began.

Electrophysiological recording and behavioral procedures. Most of the details of the electrophysiological recording techniques are as described in McNaughton et al. (1986). The electrical stimuli consisted of 200 $\mu \mathrm{sec}$ diphasic, constant current pulses given at a stimulus intensity range of $200-500 \mu \mathrm{A}$. The low-frequency test stimulation was given at least $5 \mathrm{sec}$ apart between hemispheres and 10-20 sec apart within a given hemisphere. The total number of stimulus pulses and stimulus intensities were always matched betwecn low-frequency hemispheres and high-frequency hemispheres within a given rat. The high-frequency stimulation parameters used for most of these studies consisted of 10 repetitions of a $25 \mathrm{msec}$ train (i.e., 10 pulses) delivered at $400 \mathrm{H} /$, for a total of 100 pulses (10-train stimulus pattern). One additional highfrequency protocol was used in which there were 50 repetitions of a 20 msec train (i.e., 8 pulses) delivered at $400 \mathrm{~Hz}$, for a total of 400 pulses (50-train stimulus pattern).

All response data were digitized by computer at $20 \mathrm{kHz}$ and stored on disk for subsequent off-line analysis. The field excitatory postsynaptic potential (EPSP) amplitude was measured as the voltage difference be- 
Figure 1. Electrical recordings of the LTE paradigm. The tracings are examples of perforant path evoked responses and EEG recorded in the hilus of the fascia dentata, before (top), during (for evoked responses) or immediate after (for EEG) HF stimulation (middle), and $30 \mathrm{~min}$ following the 10 train stimulation session (bottom). The example on the left illustrates a case in which no afterdischarge is observed and demonstrates robust enhancement of the population spike $30 \mathrm{~min}$ after the $\mathrm{LTE}$ stimulus. On the right, a case is illustrated in which an afterdischarge was elicited by the HF stimuli. No rats were included among the present experimental animals if they exhibited such afterdischarge. Calibration bars: evoked responses, $5 \mathrm{mV}, 5 \mathrm{msec}$; EEG, $0.5 \mathrm{mV}, 400 \mathrm{msec}$.
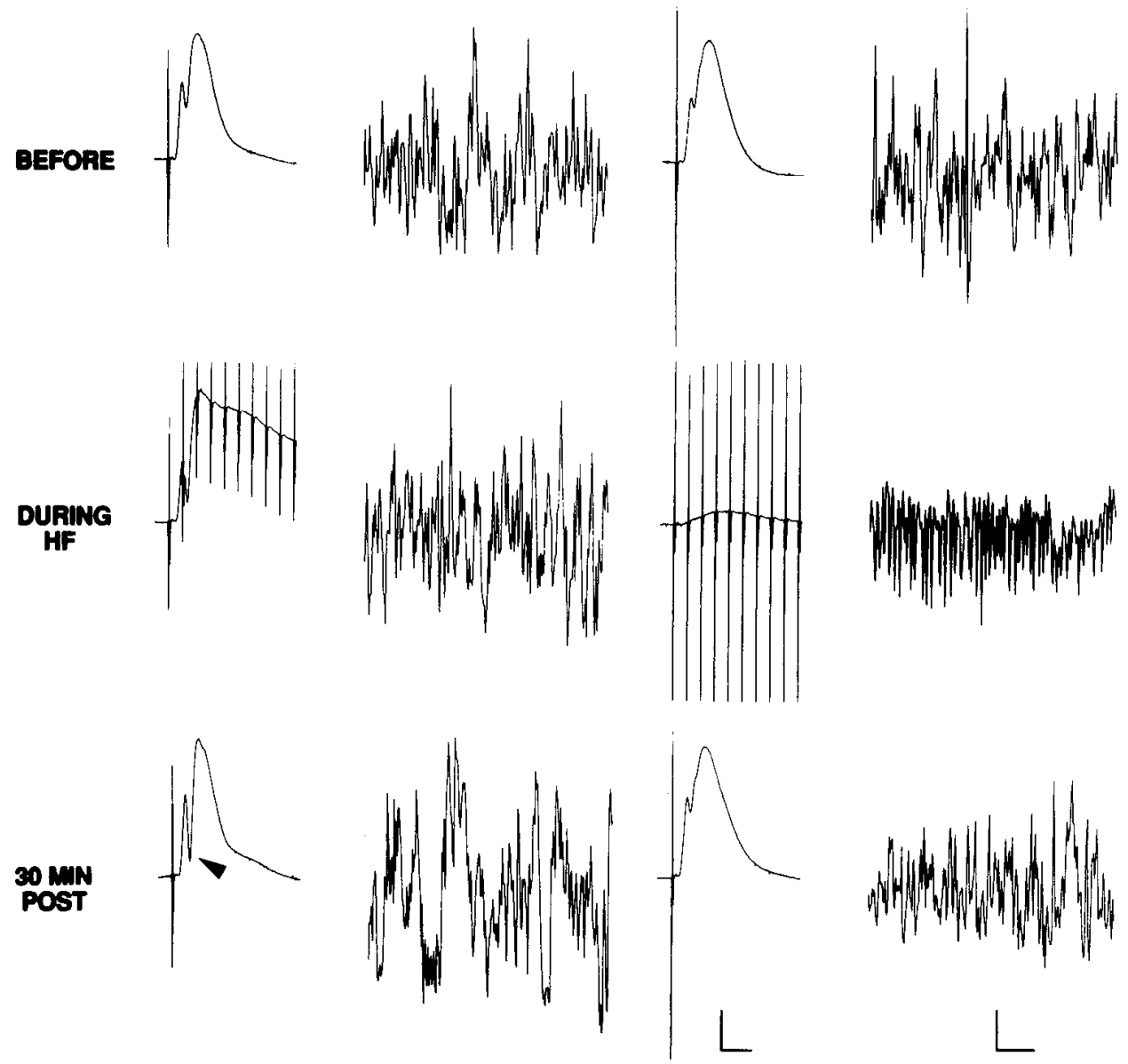

tween two cursors set at approximate EPSP onset and $1 \mathrm{msec}$ beyond this point. The population spike was measured as the area under the tangent line marking the onset and offset of the negative-going spike. To calculate the amount of change observed at various time points following high- or low-frequency stimulation, the fractional change was computed by the formula $\left(V_{t}-V_{0}\right) / V_{0}$, where $V_{t}$ is the value after highfrequency (or low-frequency in control hemispheres) stimulation and $V_{0}$ is the mean baseline value before the treatment. In addition to evoked responses, EEG data were collected for $2.56 \mathrm{sec}$ before each stimulus delivery. EEG was also monitored on analog oscilloscopes. These procedures enabled careful monitoring for possible afterdischarge following the high-frequency treatment. Examples of evoked responses and EEG collected in two different experiments are shown in Figure 1.

For the eight old animals participating in the experiment, and the corresponding eight young control rats, spatial behavioral tests were administered using the Morris swim task (Morris, 1981). A total of nine trials were given on each of $2 \mathrm{~d}$, essentially as described previously (McNaughton et al., 1989). 'This was done simply as a screening procedure to ensure that the old rats included in this experiment exhibited expected spatial memory deficits (i.e., Gallagher and Pelleymounter, 1988).

In situ hybridization. In situ hybridization techniques have been described previously (Saffen et al., 1988; Cole et al., 1989, 1990). Rats were killed by guillotine decapitation, and brains were rapidly removed ( $<2 \mathrm{~min}$ ) and collected on wet ice. Histological tissue blocks were prepared by combining half-brains from naive controls and MECS controls along with the experimental animals. This procedure provides a positive control on each tissue section and allows a comparative analysis of the magnitude of LTE-induced responses. Tissue blocks were rapidly frozen in plastic molds on dry ice/ethanol. Care was taken to assure that the postmortem interval prior to freezing was less than $10 \mathrm{~min}$.

${ }^{35} \mathrm{~S}$ riboprobes were prepared using $\mathrm{T}_{3}$ or $\mathrm{T}_{7}$ RNA polymerase from appropriately restricted plasmids containing mouse [c-jun, jun $\mathrm{B}$, fos $\mathrm{B}$
(Nakabeppu and Nathan, 1991), nur77 (Hazel et al., 1988), Krox20 (Chavner et al., 1989)], rat (NGFI-A), or human (c-fos) cDNA inserts of the transcription factors (Saffen et al., 1988). In certain experiments, we also used ${ }^{35} \mathrm{~S}$ - or ${ }^{32} \mathrm{P}$-labeled $\mathrm{cDNA}$ probes prepared by random priming of near full-length cDNA inserts. When cDNA probes were used for in situ hybridization, probes were heat denatured and $0.1 \mu \mathrm{g} /$ $\mathrm{ml}$ of sheared salmon sperm was added to the standard hybridization buffer. Slides were hybridized overnight at $50^{\circ} \mathrm{C}$ and washed in $2 \times$ saline-sodium citrate (SSC) twice for $20 \mathrm{~min}$ at room temperature and then $30-60 \mathrm{~min}$ at $45^{\circ} \mathrm{C}$ in $4 \times \mathrm{SSC}, 50 \%$ formamide followed by a brief dip in $\mathrm{H}_{2} \mathrm{O}$ and dehydration in ascending ethanol. Exposure times were typically comparable to sections labeled with ${ }^{35} \mathrm{~S}$ riboprobes.

Immunohistochemistry. Affinity-purified rabbit polyclonal antisera selective for Zif 268 (provided by Dr. Barbara Christy, University of Texas Health Science Center, San Antonio, TX) or JunB (provided by Dr. Yusaku Nakabeppu, Kyushu University, Fukuoka, Japan) were used for immunohistochemical staining of postfixed, fresh-frozen brain sections, as described previously (Worley et al., 1990, 1991). This protocol allows us to use adjacent sections of the same histological material for both in situ hybridization and immunohistochemistry.

\section{Results}

\section{Electrode implantation and basal expression of transcription} factors

Acute brain injury causes a rapid, NMDA-dependent induction of several transcription factors including $\mathrm{c}-f o s, \mathrm{c}-j u n, j u n \mathrm{~B}$, and zif 268 (Dragunow et al., 1990; Cole et al., in press). To examine possible chronic changes due to electrode implantation, we analyzed four adult rats and one old rat that were implanted and allowed to recover for at least 2 weeks before death. The animals 

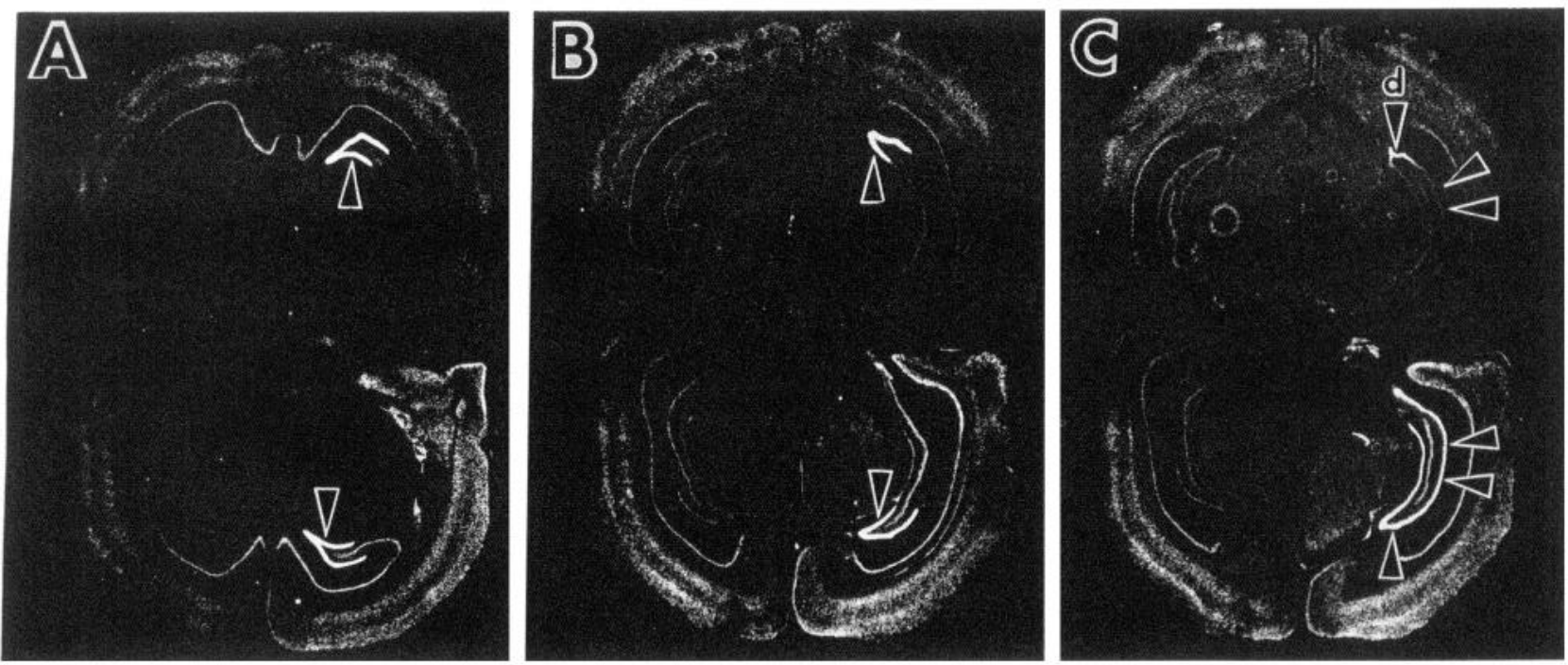

Figure 2. LTE induces zif $268 \mathrm{mRNA}$ in a discrete region of the dentate gyrus. $A-C$ are autoradiograms of zif 268 in situ hybridization to rat brain sections. Each autoradiogram includes the experimental brain (top), as well as half-brains from a naive control (bottom left) and a seizure-stimulated control (30 min after MECS; bottom right), which are included for anatomical comparison and technical control. The experimental animal was killed 30 min after 80 pulses of LF (left fascia dentata) and HF (10-train stimulus, right fascia dentata) perforant path stimulation (see Materials and Methods for stimulation protocol). Panels are from the same animal and demonstrate the anatomic distribution of the zif268 mRNA response to the HF stimulus. Note increases in zif $268 \mathrm{mRNA}$ in the granule cell layer of the dorsal hippocampus $(A$ and $B$, upper arrowheads) are as robust as those induced by a seizure ( $A$ and B, lower arrowheads). LTE-induced increases are detected in a small, dorsal region of the caudal hippocampus $(C$, arrowhead with $d)$ while levels in the remainder of the caudal hippocampus $(C$, upper double arrowheads) are not induced. By contrast, seizures induce zif 268 in the granule cell layer throughout the hippocampus including the caudal region (C, lower arrowheads); 10-train LTE produced similar robust, but anatomically restricted induction of zif $268 \mathrm{mRNA}$ in each of two additional animals that were sectioned at multiple anatomic levels. The seizure-induced response is present in the dentate gyrus throughout the extent of the hippocampus.

were each connected to the recording apparatus without stimulation before death. Brains were blocked, cut, and mounted on slides with nonoperated controls. Coronal sections including several regions of the hippocampus and entorhinal cortex were examined by Nissl stain (toluidine blue) and by in situ hybridization. The recording electrode implantation site was detected histologically as a track through the cortex and hippocampus ending in the hilus of the fascia dentata. No areas of gross cavitation or hemosiderin staining were detected. The stimulating electrode tracks in the entorhinal cortex and angular bundle were similarly pale. mRNA levels of c-fos, c-jun, jun B, and zif 268 in the implanted hemisphere were identical to those in either the nonimplanted hemisphere or the naive control. In this in situ analysis, we were particularly careful to examine granule cells of the dorsal hippocampus in the immediate vicinity of the recording electrode and several millimeters rostral and caudal to the site.

\section{Transcription factor induction following electrically induced afterdischarges}

The EEG was routinely monitored before and after the HF stimulation in order to exclude preparations in which afterdischarges might be induced (McNaughton et al., 1986). In four young and one old rat, a single afterdischarge was detected following the HF stimulation. An example of the electrophysiological data obtained from a rat with no afterdischarges and from one that did exhibit afterdischarge is shown in Figure 1. The animals with afterdischarge were killed $30 \mathrm{~min}$ or $1 \mathrm{hr}$ following the HF stimulation, at which time the depression due to the afterdischarge had recovered, and the responses were enhanced compared to baseline. mRNA levels of all assayed transcription factors (zif 268, c-fos, c-jun, jun B, nur77, Krox20, and $f o s \mathrm{~B}$ ) were strongly induced in granule cells of the hippocampus (data not shown). The response appeared identical to that induced by seizures in all cases. Induction of transcription factor mRNA was restricted to the hippocampus ipsilateral to the afterdischarge, which corresponds with the lack of change in the evoked response observed in the hemisphere contralateral to the afterdischarge event. No changes were detected in overlying cortex. These rats are not included in the data presented below.

\section{Synaptic depolarization and transcription factor expression}

The effect of orthodromic monosynaptic stimulation of hippocampal granule cells was examined. These experiments were designed to confirm, in the chronic preparation, that transcription factors are induced by high-frequency (HF) but not lowfrequency (LF) synaptic depolarizations. In the present protocol, identical numbers and intensities of orthodromic stimuli were administered in the LF and HF preparations (i.e., the only difference was the frequency and temporal pattern of stimulus delivery). In two bilaterally prepared rats that received unilateral LF stimulation (no stimulation in the other hemisphere), no changes in transcription factor mRNA were detected compared with naive control brains mounted on the same slide. In these experiments, the brains were obtained $30 \mathrm{~min}$ after initiation of LF stimulation and $10 \mathrm{~min}$ after the last stimulus.

By contrast, in rats receiving HF stimulation, 10 of 10 preparations assayed at $30 \mathrm{~min}$, and 7 of 7 assayed at $1 \mathrm{hr}$, showed strong induction of zif $268 \mathrm{mRNA}$ in hippocampal granule cells (Fig. 2, Table 1). The mean fractional change in EPSP measured approximately 30 or $60 \mathrm{~min}$ after the HF stimulation was 0.43 $( \pm 0.04$ SEM) and $0.39( \pm 0.06$ SEM), respectively, compared with baseline. The population spike was also significantly ele- 
Table 1. Increases in transcription factor mRNA induced $30 \mathrm{~min}$ after either a 10-train or 50-train LTE stimulus are expressed as a percentage of seizure-induced increases

\begin{tabular}{|c|c|c|c|c|}
\hline Animal & zif 268 & $j u n \mathrm{~B}$ & c-fos & $c-j u n$ \\
\hline \multicolumn{5}{|l|}{10 Train } \\
\hline 2282 & 105 & 50 & 0 & 0 \\
\hline 2278 & 65 & 28 & -12 & 15 \\
\hline 2277 & 50 & 90 & 0 & 0 \\
\hline 2287 & 64 & 46 & -15 & -22 \\
\hline 2283 & 100 & 52 & 2 & 5 \\
\hline 2284 & 115 & 52 & 5 & 20 \\
\hline Mean \pm SEM & $83 \pm 27$ & $53 \pm 20$ & $-3 \pm 8$ & $3 \pm 15$ \\
\hline \multicolumn{5}{|l|}{50 Train } \\
\hline $3283^{*}$ & 103 & 114 & 70 & 50 \\
\hline 3375 & 100 & 81 & 41 & 50 \\
\hline 3341 & 130 & 86 & 37 & 56 \\
\hline $3282^{*}$ & 115 & 61 & 47 & 17 \\
\hline 3369 & 68 & 106 & 90 & 33 \\
\hline 3379 & 111 & 102 & 100 & 33 \\
\hline Mean \pm SEM & $105 \pm 21$ & $92 \pm 19$ & $64 \pm 27$ & $40 \pm 15$ \\
\hline
\end{tabular}

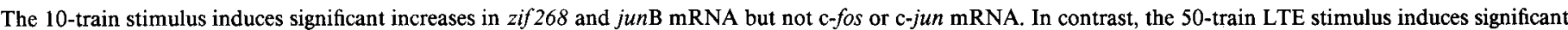

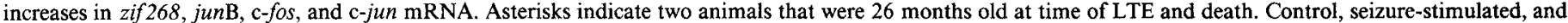

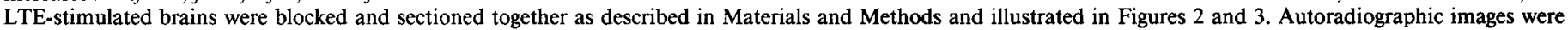

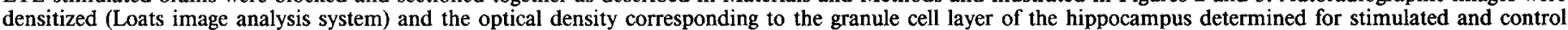

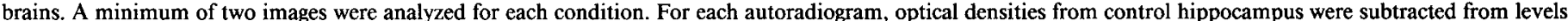

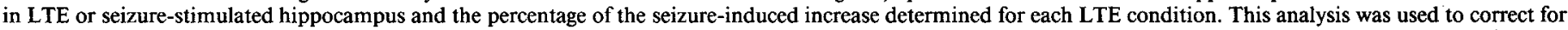

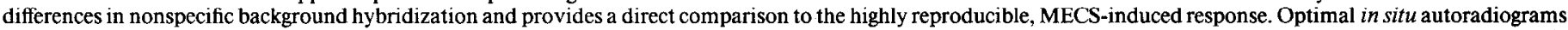

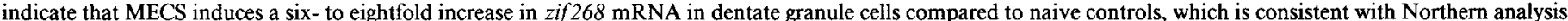

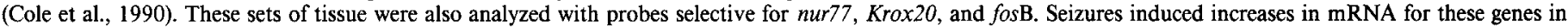

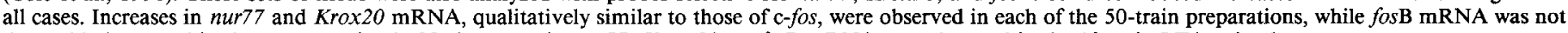
detectably increased in these same animals. No increases in nur77, Krox 20, or fosB mRNA were detected in the 10-train LTA animals.

vated. The zif $268 \mathrm{mRNA}$ response was restricted to granule cells of the dorsal hippocampus in a region $\sim 2 \mathrm{~mm}$ rostral and caudal to the recording site. No changes in zif $268 \mathrm{mRNA}$ levels were detected in the cortex overlying the recording site $(n=17)$ or in the entorhinal cortex that contains cells of origin of the perforant pathway $(n=3)$. Because experimental brains were routinely blocked with naive control and seizure-stimulated (30 min after pentylenetetrazol or MECS) brains, we were able to assess the magnitude of the mRNA response in relation to these controls. In all cases, the zif $268 \mathrm{mRNA}$ increase following the HF stimulus was comparable in magnitude to the seizure response (Table 1). Of the other transcription factors, only jun B mRNA was increased by the HF stimulus (Fig. 3). This response was observed in all HF preparations but, unlike the zif 268 response, the jun $\mathrm{B}$ response was less robust than that obtained following MECS. mRNA levels of c-fos, c-jun, nur77, Krox20, or fos B were not detectably increased in any of the preparations.

In eight rats (subset of the 10 -train, 30 min sacrifice group above), HF and LF stimuli were administered to separate hemispheres of the same animal. As anticipated, the pathway that received $\mathrm{HF}$ stimuli displayed enhanced synaptic responses (see above), while the LF pathway did not (fractional change of the EPSP, $0.04 \pm 0.03$ ). Transcription factor responses in the HF hemisphere were identical to those that received only a unilateral HF stimulus. In three of these preparations, granule cells of the fascia dentata ipsilateral to the LF stimulus demonstrated modest increases of zif 268 mRNA relative to naive control hippocampus. In all cases, increases in the LF side were less intense than on the HF side of the hippocampus. The pattern of induction was punctate, indicating that only a minority of the cells responded. mRNA levels of $j u n \mathrm{~B}$ ipsilateral to the LF stimulus were identical to naive controls in these preparations.

\section{Zif 268 and JunB immunohistochemistry}

Zif 268- and JunB-selective rabbit polyclonal antisera were used to assess the response of the transcription factor proteins. In each of three animals killed $1 \mathrm{hr}$ after a 10-train LTE stimulus, we observed robust increases in 7if 268 immunoreactivity. Immunostaining was present in nuclei of essentially all of the granule cells that received the HF stimulus (Fig. 4). Immunostaining was comparable in intensity to that detected $1 \mathrm{hr}$ after a seizure. By contrast, no detectable increase in JunB immunostaining was detected in these same preparations, despite robust seizure-induced increases in JunB immunostaining. Robust JunB immunostaining was detected in an animal $1 \mathrm{hr}$ following a single afterdischarge.

\section{Stimulus parameters that can induce $c$-fos as well as zif 268}

Our observations indicate that zif $268 \mathrm{mRNA}$ but not c-fos mRNA is increased in granule cells by a synaptic stimulus sufficient to induce LTE (10-train stimulus pattern). By contrast, a previous report has suggested that $c$-fos can be induced in conjunction with LTE in chronically implanted, unanesthetized rats in the absence of afterdischarges in the FFG (Dragunow et al., 1989; Jeffery et al., 1990). These studies, however, used substantially more stimulus pulses than the 10-train stimulus used here. To determine whether the differences in the c-fos response in our studies were due to the number of HF stimulus trains, we reproduced (in five rats) the stimulus parameters used in the studies that have reported c-fos induction (i.e., 50 trains). 

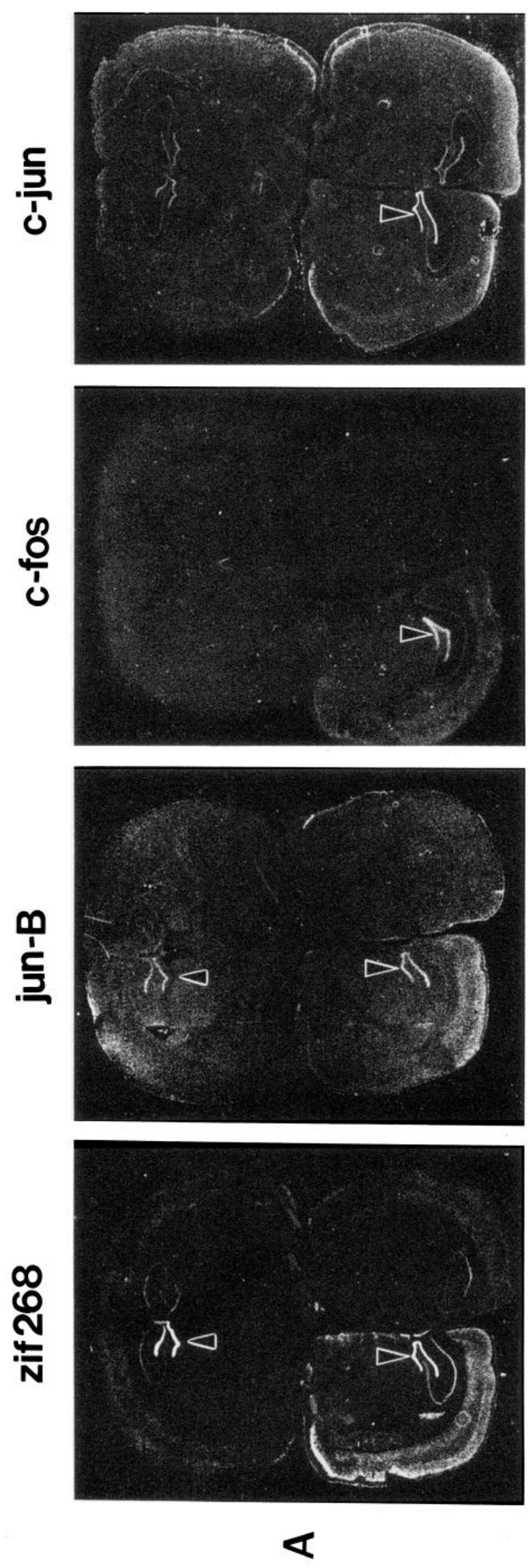
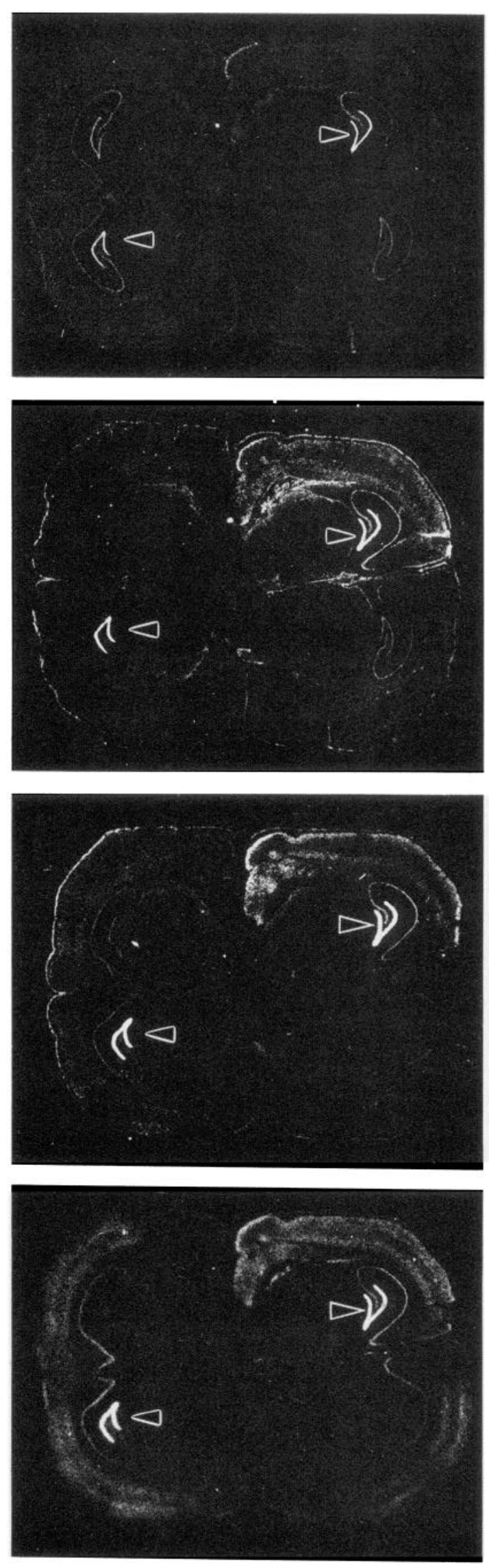

$\infty$

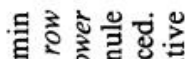

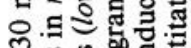

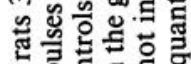

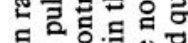

× $\infty$ 는

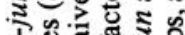

次焉离。

몰리잉

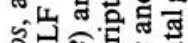

넝

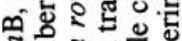

롳도을

조

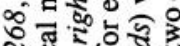

소웛

은므으뭉

듣ำ 통

융 항 ‘

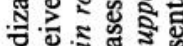

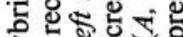

드용

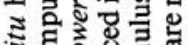

के 듀을 튼

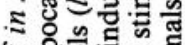

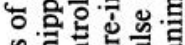

츠늘 을

픙ㅇㅇ웡

일 논

월 \&

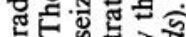

요

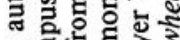

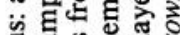

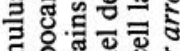

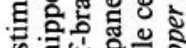

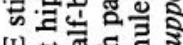

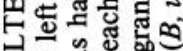

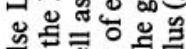

호잋을

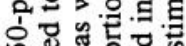

类

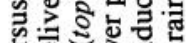

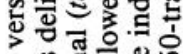

๘

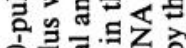

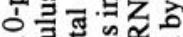

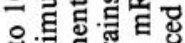

을

乩它高

업ㅂㅗㅀㅗ.

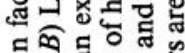

สิ สี $\infty$

ํํㅇ \&

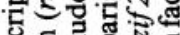

들을 눙므

్ㅗㄴ

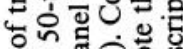

เ

음ㄴ.

ธิ ชี

产

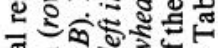
खु.

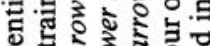
क्षे का

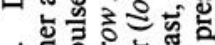

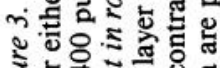

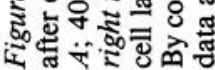



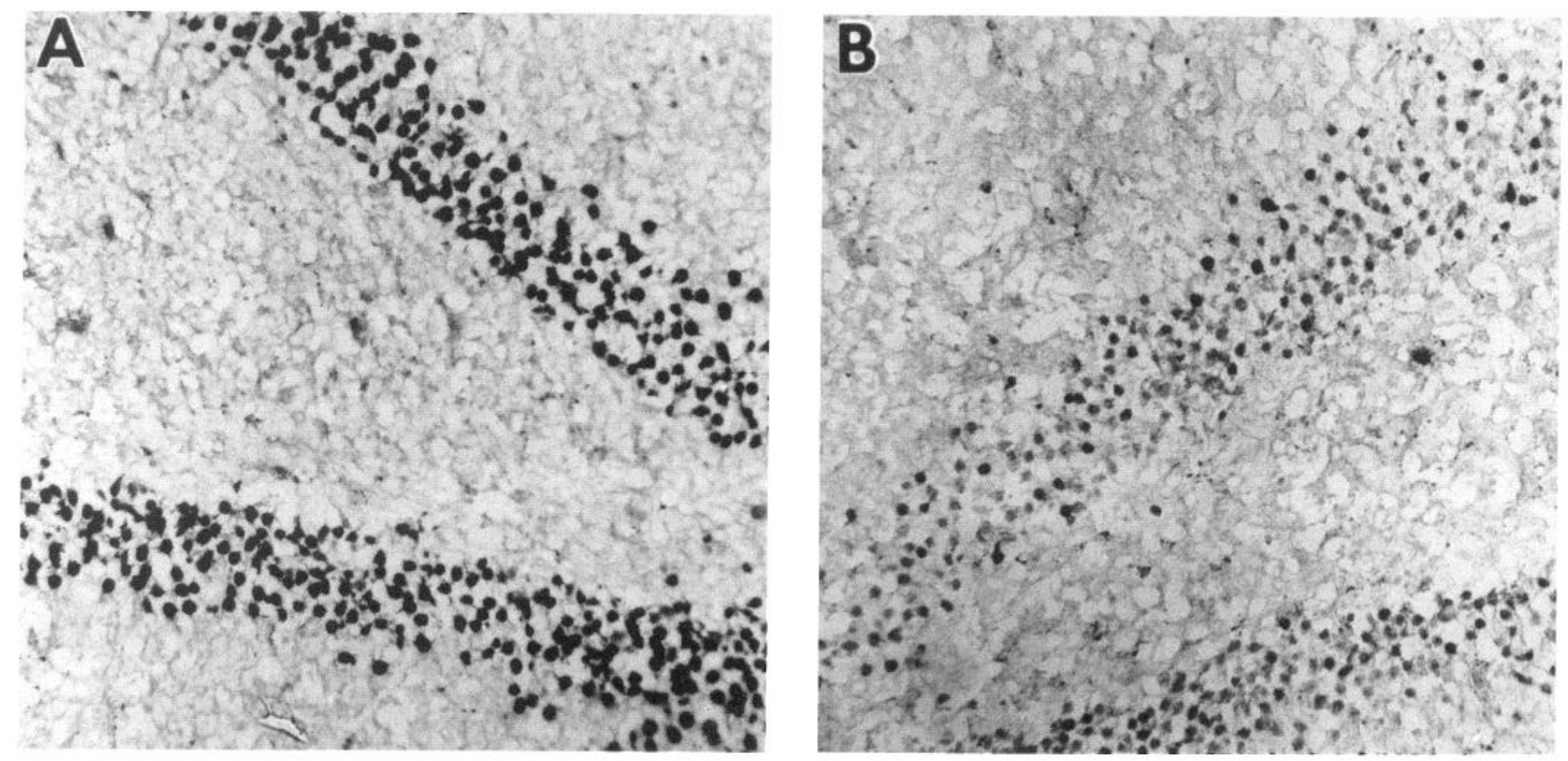

Figure 4. Zif 268 immunoreactivity is induced by LTE in granule cell neurons: photomicrographs $(\sim 100 \times)$ of Zif 268 immunoreactivity (ABC peroxidase) in the fascia dentata from an animal $1 \mathrm{hr}$ following a unilateral 10-train LTE stimulus to the left hippocampus $(A)$. The right fascia dentata had a chronically implanted recording electrode but was not stimulated $(B)$. Note intense staining in all granule cells of the stimulated fascia dentata. Observation at high power confirms that inducible staining is associated with the nucleus. Identical immunostaining was observed in each of three rats tested. JunB immunoreactivity was not detectably increased in these LTE-stimulated animals.

No afterdischarges were produced in these animals. Confirming previous reports, c-fos mRNA was increased in granule cells stimulated with these parameters. No response was detected in the contralateral hippocampus that received LF only or in the cortex overlying the stimulating electrode. The magnitude of the c-fos mRNA increase was, in each case, less than that induced by MECS (Fig. 3, Table 1). As in preparations that received the 10-train stimulation, zif 268 mRNA increases after the 50-train stimulus parameters were similar to seizure-induced increases. JunB mRNA was strongly induced by the 50 -train stimulus parameters to levels comparable to seizureinduced increases, while c-jun, nur77, and krox 20 mRNA increases were less robust than those observed in MECS animals. fos B mRNA was strongly induced by MECS but not detectably increased by the 50 -train HF stimulus.

\section{NMDA dependence of the transcription factor response to $H F$ stimuli}

MK-801 is a noncompetitive NMDA antagonist that blocks LTE following systemic administration (Abraham and Mason, 1988). In the acute recording preparation, MK-801 blocks increases in transcription factor mRNA induced by HF stimuli (Cole et al., 1989; Wisden et al., 1990). To confirm that the transcription factor response to HF stimuli is NMDA dependent in the unanesthetized chronic preparation, we administered MK$801(1 \mathrm{mg} / \mathrm{kg}$, i.p.) $30 \mathrm{~min}$ prior to the 10 -train $\mathrm{HF}$ stimulus given to four rats. In three of four preparations, MK-801 produced a modest $(\sim 20 \%)$ reduction of the LF postsynaptic response and the perforant path stimulus intensity was adjusted to restore the amplitude of the postsynaptic response to that recorded prior to MK-801 administration. LTE assayed $25 \mathrm{~min}$ after the HF stimulus was blocked in part in one rat (fractional change of EPSP, 0.16) and completely in two other rats (mean fractional change, -0.08 ). Animals were killed $30 \mathrm{~min}$ after the $\mathrm{HF}$ stimulus and transcription factor mRNA was assayed. Zif 268 mRNA was weakly induced in the one animal with a partial block of LTE and not induced in the two with complete block. In the fourth animal, MK-801 administration had no effect on LF responses, and did not block LTE or induction of zif 268 . This rat also did not display the characteristic motor effects that typically follow MK-801 administration. This result was therefore attributed to ineffective delivery of the drug.

Our data indicates that the 50 -train stimulus produces a broader activation of transcription factors than does the 10train stimulus. To assess whether the response to the 50-train stimulus is dependent on NMDA receptor activation, we treated two animals with MK-801 (1 mg/kg, i.p.) $1 \mathrm{hr}$ prior to a $50-$ train stimulus. A $1 \mathrm{hr}$, rather than $30 \mathrm{~min}$, preinjection period was used in order to increase the probability of complete blockade of LTE by MK-801. Both animals demonstrated characteristic behavioral effects of MK-801. mRNA responses for each of inducible transcription factors, including zif 268 , c-fos, c-jun, junB, nur77, and Krox20, were blocked in these animals. We conclude that transcription factor induction by either the 10train or the 50-train stimulus is dependent on NMDA receptor activation.

\section{LTE duration: correlation with stimulus parameters}

The 10-train stimulus parameters used in all but the preceding experiment reproducibly induce LTE lasting several days (Barnes, 1979). Because the 50-train stimulus parameters elicit increases in transcription factors that are not induced with 10 trains, we examined possible differences in LTE duration. Twenty bilaterally implanted rats were randomly assigned to receive either 


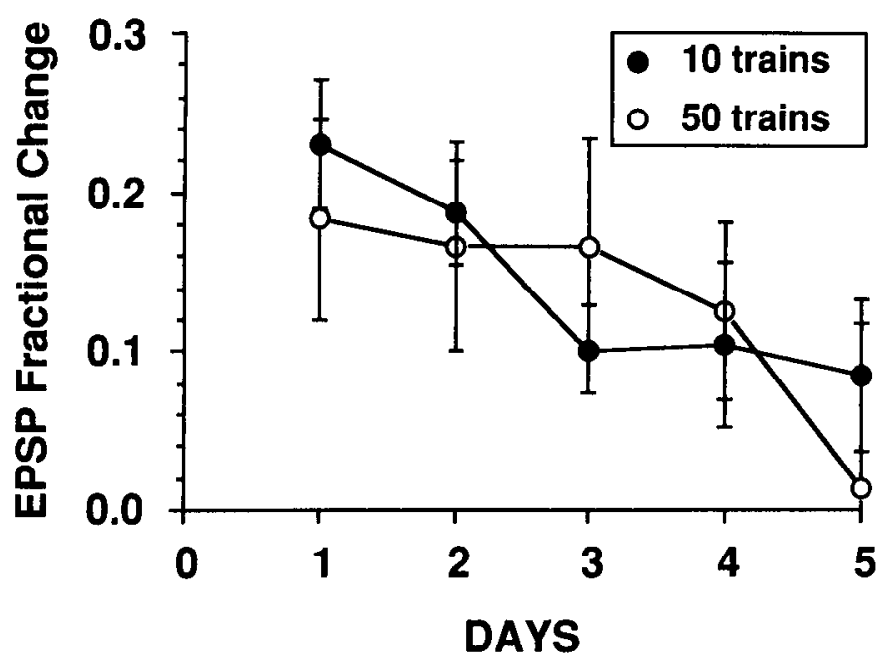

Figure 5. Mean EPSP (and SEM) fractional change of rats receiving either the 10- or 50-train stimulus pattern (see Materials and Methods) on day 0 . Neither the initial magnitude of LTE induction nor its decay was statistically different between stimulation treatment groups.

10 or 50 stimulus trains in one hemisphere (half of the rats in each treatment group). The opposite hemisphere was given LF control stimulation. Following induction and decay of enhancement in that hemisphere, the hemisphere that initially received LF stimulation was given the opposite treatment. The other hemisphere then served as the LF control. Robust enhancement was induced in all 40 hemispheres (Fig. 5), and no afterdischarges were induced. There was no difference in the initial magnitude of LTE between the 10- and 50-train groups assayed $1 \mathrm{hr}$ following stimulation $\left(F_{\mathrm{I} .40}=0.428, p>0.05\right)$. Additionally, there was no statistical difference in the rate of LTE decay over days $\left(F_{1,40}=0.182, p>0.05\right)$. The average decay half-time was 4.67 and $3.64 \mathrm{~d}$ for the 10 - and 50-train groups, respectively (Fig. 5).

\section{Zif 268 response in aged rats and performance in Morris swim task}

Zif 268 mRNA responses were examined in aged animals to determine if alterations in zif 268 induction are associated with the known deficit in maintenance of LTE in old rats (Barnes, 1979). Four 24-month-old behaviorally impaired rats (see Fig. 6) received the standard 10-train stimulus, and were killed 30 min later. These animals each exhibited substantial enhancement $30 \mathrm{~min}$ after stimulation ( $n=$ mean fractional change EPSP, $0.44 \pm 0.09$ SEM) and for in situ analysis were blocked and sectioned together with 9-12 month animals that received the identical stimulus. Age-matched naive control and seizurestimulated animals were also included in the tissue block. LTEand MECS-induced increases in zif 268 and $j u n \mathrm{~B}$ mRNA were qualitatively similar in young and old animals. Quantitation of the in situ autoradiograms indicated that zif $268 \mathrm{mRNA}$ was induced to levels similar to those in the young animals (young: $71 \% \pm 29, n=4$; old: $56 \% \pm 20, n=4$ ). Two additional old rats received the 50 -train stimulus parameters. These animals showed equivalent inductions of zif $268, j u n \mathrm{~B}, \mathrm{c}-j u n$, and c-fos mRNA as in their young counterparts (Table 1).

\section{Discussion}

The major findings of this study are that the transcription factor response induced in association with synaptic LTE in the hip-

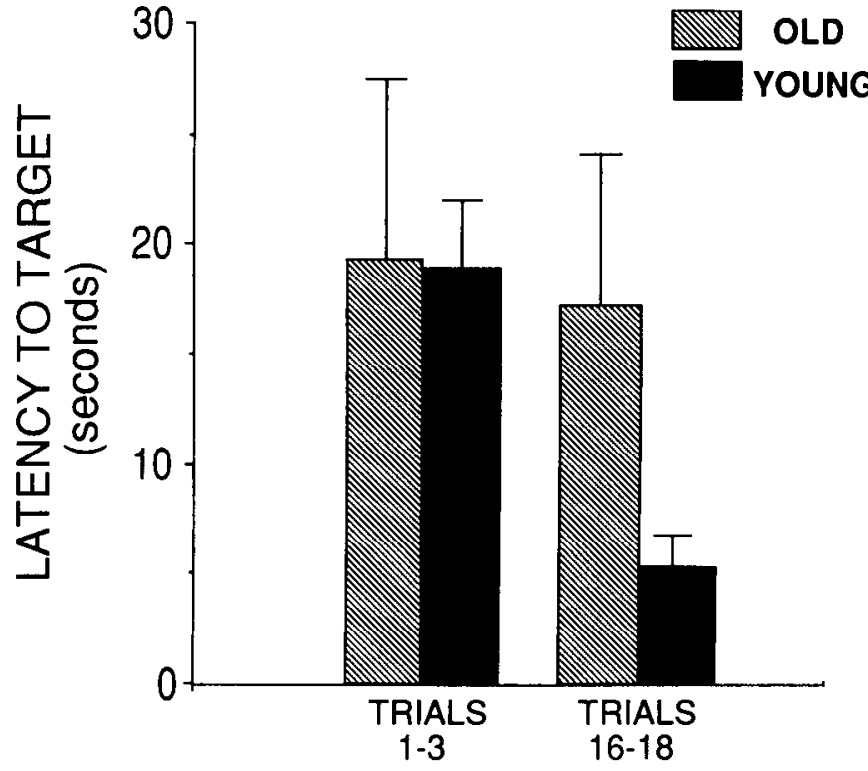

Figure 6. Performance scores from the eight old and eight young control rats tested on the spatial version of the Morris water task. Data shown are latencies to find the hidden platform in the pool on the first and last three trials of training on the task. For both latency and pathlength (not shown) measurements the young rats performed significantly better by the end of training than did the old rats.

pocampus is highly reproducible in chronically prepared rats, and involves a selective, robust increase in zif $268 \mathrm{mRNA}$ levels and immunoreactivity. This study confirms earlier observations that transcription factors are inducible in hippocampal granule cells by HF synaptic stimuli (Douglas et al., 1988; Cole et al., 1989; Dragunow et al., 1989; Jeffrey et al., 1990; Wisden et al., 1990; Schreiber et al., 1991; Abraham et al., 1992; Richardson et al., 1992). Zif $268 \mathrm{mRNA}$ levels were increased in hippocampal cells $30 \mathrm{~min}$ after a standard 10-train LTE stimulus. This stimulus was determined previously to induce durable enhancement in a single stimulus session (Barnes, 1979). In the same animals, there was no detectable change in c-fos, c-jun, or other transcription factors inducible by seizures, including nur 77 , Krox20, and fosB (Watson and Milbrandt, 1989; Nakabeppu and Nathans, 1991; Bhat et al., 1992; Mack et al., 1992). The magnitude of the zif $268 \mathrm{mRNA}$ increase was also highly reproducible and similar to increases induced by either pentylenetetrazol or MECS. JunB mRNA was also reproducibly induced in these preparations; however, the magnitude of the response was invariably less than seizure-induced increases. Additionally, no induction of JunB immunoreactivity was detected following HF stimulation despite detection of robust seizure-induced increases. The inability to detect an LTE-induced increase in JunB immunoreactivity despite modest increases in jun B mRNA may be due to differences in the sensitivity of the histological techniques or may represent an example of $m R N A$ changes without corresponding changes in protein. The transcription factor response to this LTE-inducing stimulation appears qualitatively different from the response to scizurcs, since zif 268 is comparably induced by both the LTE stimulus and seizures, while other transcription factors exhibit either markedly lower or nondetectable responses to these same stimulation parameters. Interestingly, the zif $268 \mathrm{mRNA}$ response appears to be intact in aged rats, as the response to the 10-train stimulus was robust and similar to those observed in young adult rats. 
Increasing the total number of stimulus pulses from 100 to 400 (i.e., 10 trains to 50 trains) resulted in detectable increases in c-fos, c-jun, nur77, Krox20, junB, and zif 268 mRNAs. Increases in c-fos, c-jun, nur77, and Krox20 mRNAs resulting from the 50-train stimulus were typically less than those induced by seizures, while zif 268 and junB mRNA responses to these stimuli were identical. The general activation of transcription factors with the 50-train stimulus is consistent with previous studies reporting increases in c-fos mRNA (Dragunow et al., 1989; Jeffery et al., 1990) and immunostaining for these transcription factors (Abraham et al., 1992) accompanying LTE induction. Unlike the results of D'Costa et al. (1991), who found diminished c-fos activity in old mice following electroconvulsive shock, the old, memory-deficient rats in the present experiments exhibited robust activation of $c$-fos with the 50-train stimulus parameters, and following MECS.

Differences in the transcription factor response to 10- and 50train stimuli presumably reflect the differential activation of signaling pathways that may be involved in LTE of synaptic potentials. Accordingly, we compared the induction and decay of LTE following 10- and 50-train stimulus protocols. No statistically significant differences in either the initial induction or the durability of enhancement were observed despite a relatively large sample population ( 40 hemispheres, 20 rats). This result suggests that critical signaling pathways involved in LTE are equally activated by 10 - and 50 -train stimuli and reinforces the special correlation between induction of zif 268 and LTE.

In contrast to the present results, Abraham and coworkers (Jeffery et al., 1990; Abraham et al., 1992) have reported an increase in LTE duration following 50-trains of HF stimulus pulses compared to 10-train stimulus parameters, and suggested that this difference in LTE duration represents an electrophysiological correlate of the induction of c-fos and other transcription factors. Our data do not support this hypothesis. Using within-animal comparisons of the two stimulus parameters in a group of 20 animals, we found no differences in the durability of LTE with the different stimulus protocols, in spite of the differential transcription factor activation. Resolution of this apparent discrepancy clearly will require further study.

Consistent with previous reports (Cole et al., 1989; Wisden et al., 1990), systemic administration of MK-801, a noncompetitive NMDA-type glutamate antagonist, blocked both LTE and zif $268 \mathrm{mRNA}$ increases following a 10-train stimulus. MK801 also blocked LTE and zif $268, j u n \mathrm{~B}, \mathrm{c}-f o s, \mathrm{c}-j u n, n u r 77$, and Krox20 mRNA increases following the 50-train stimulus. It therefore appears that each of these genes may be induced in the hippocampus by NMDA-dependent pathways; however, our data suggest that junB, c-fos, c-jun, nur77, and Krox 20 mRNA increases may be linked to processes other than I.TF induction or maintenance. Zif 268 is also selectively responsive to afferent synaptic activity in the visual cortex, where basal expression of zif 268 , but not $\mathrm{c}$-fos, is rapidly reduced following administration of NMDA receptor antagonists (Worley et al., 1991). Accordingly, in both the hippocampus and neocortex, zif 268 appears to be tightly linked to physiological levels of NMDA receptor activation. The present study demonstrates that different transcription factors possess distinct thresholds for synaptic activation and that zif 268 is most highly correlated with the LTE phenomena. It is important to note that this relationship was defined in a single synaptic system. In other systems, c-fos and zif 268 are coordinately induced by several natural stimuli (Aronin et al., 1990; Rusak et al., 1990; Tischmeyer et al., 1990;
Anokhin et al., 1991; Nikolaev et al., 1992), suggesting that mechanisms coupling synaptic events with changes in gene expression may be specific to both the neuronal population and to the type of stimulus.

The high degree of reproducibility of results in the present study are almost certainly due to the technical advantages of the chronic preparation. Transcription factor responses were monitored scveral wecks after electrode implantation and were not complicated by possible effects of acute injury. Effects of anesthesia, which can alter transcription factor expression (Dragunow et al., 1989; Jeffery et al., 1990), were also avoided. Recording stability was enhanced since there is no acute brain swelling due to injury or shrinkage due to surgery and attendant osmotic shifts. Responses were restricted to the dorsal hippocampus and not observed in the ipsilateral cortex, as was typically the case in the acute preparation (Cole et al., 1989; Wisden et al., 1990), presumably due to acute injury associated with electrode placement. In nearly all the preparations, mRNA responses were strictly ipsilateral to the HF stimulus. However, in a subset (three of eight) of preparations that received both HF and LF stimuli, we detected modest increases in zif 268 mRNA in granule cells ipsilateral to the LF stimulus. The mechanism of this response remains unknown but might involve crossed perforant pathway projections or hippocampal commissure connections (Goldowitz et al., 1975). The observation that the LTE-induced transcription factor response is restricted to the dorsal hippocampus confirms previous observations (Cole et al., 1989) and is consistent with the restricted distribution of perforant path afferents to the dentate gyrus (Hjorth-Simonsen and Jeune, 1972). Optimization of electrophysiological responses at the recording electrode during electrode placement would serve to activate selectively projections to the dorsal hippocampus. The restricted distribution of this response may be helpful in interpreting results of experiments that use the LTE paradigm to modify certain spatial learning behaviors that are dependent on the hippocampus (Korol et al., 1993).

Observations in the present study help define thresholds for synaptic activation of transcription factors in the hippocampus and indicate that induction of zif 268 and LTE are triggered by similar patterns of synaptic stimulation. These correlative data suggest a role for zif 268 in the LTE phenomena. Further studies comparing the thresholds for LTE and zif 268 induction would strengthen the association. Nevertheless, our studies indicate that the genomic response to synaptic stimuli sufficient to induce LTE is less complex than that induced by more intense synaptic stimuli or seizures. Accordingly, this less intense LTE paradigm appears to be ideal for molecular studies aimed at identifying signaling pathways linking physiological NMDA receptor activation and synaptic plasticity.

\section{References}

Abraham WC, Mason SE (1988) Effects of the NMDA receptor/channel antagonists CPP and MK801 on hippocampal field potentials and long-term potentiation in anesthetized rats. Brain Res 462:40-46.

Abraham WC, Dragunow M, Tate WP (1992) The role of immediate early genes in the stabilization of long-term potentiation. Mol Neurobiol 5:297-314.

Agranoff BW (1981) Learning and memory: biochemical approaches. In: Basic neurochemistry, 3d ed (Siegel GJ, Albers RW, Agranoff BW, Katzman R, eds), p 801. Boston: Little Brown.

Anokhin KV, Mileusnic R, Shamakhina I, Rose SPR (1991) Effects of early experience on c-fos gene expression in the chick forebrain. Brain Res 544:101-107.

Aronin N, Sagar SM, Sharp FR, Schwartz WJ (1990) Light regulates 
expression of a Fos-related protein in rat suprachiasmatic nuclei. Proc Natl Acad Sci USA 87:5959-5962.

Barnes CA (1979) Memory deficits associated with senescence: a neurophysiological and behavioral study in the rat. J Comp Physiol Psychol 93:74-104

Barnes CA, McNaughton BL (1980) Spatial memory and hippocampal synaptic plasticity in middle-aged and senescent rats. In: The psychobiology of aging: problems and perspectives (Stein D, ed), pp 253272. Amsterdam: Elsevier.

Barnes CA, McNaughton BL (1985) An age comparison of the rates of acquisition and forgetting of spatial information in relation to longterm enhancement of hippocampal synapses. Behav Neurosci 99 : 1040-1080.

Barnes CA, Erickson CA, McNaughton BL, Bhat RV, Baraban JM, Worley PF (1991) Rapid induction of zif-268 mRNA is preserved in hippocampus of old F-344 rats following LTE-inducing stimulation. Soc Neurosci Abstr 17:1394.

Bhat RV, Worley PF, Cole AJ, Baraban JM (1992) Activation of zinc finger encoding gene $k r o x-20$ in adult rat brain: comparison with zif268. Mol Brain Res 13:263-266.

Bliss TVP, Lomo T (1973) Long-lasting potentiation of synaptic transmission in the dentate area of the anaesthetized rabbit following stimulation of the perforant path. J Physiol (Lond) 232:331-356.

Bullitt E (1989) Induction of c-fos-like protein within the lumbar spinal cord and thalamus of the rat following peripheral stimulation. Brain Res 493:321-397.

Chavrier P, Janssen-Timmen U, Mattei M-G, Zerial M, Bravo R, Charnay $\mathbf{P}$ (1989) Structure, chromosome location, and expression of the mouse zinc finger gene krox-20: multiple gene products and coregulation with the proto-oncogene c-fos. Mol Cell Biol 9:787-797.

Christy B, Lau LF, Nathans DM (1988) A gene activated in mouse 3 T 3 cells by serum growth factors encodes a protein with "zinc finger" sequences. Proc Natl Acad Sci USA 85:7857-7861.

Cole AJ, Saffen DW, Baraban JM, Worley PF (1989) Rapid increase of an immediate early gene messenger RNA in hippocampal neurons by synaptic NMDA receptor activation. Nature 340:474-476.

Cole AJ, Abu-Shakra S, Saffen DW, Baraban JM, Worley PF (1990) Rapid rise in transcription factor messenger RNAs in rat brain after electroshock induced seizures. J Neurochem 55:1920-1927.

Cole AJ, Worley PF, Baraban JM (in press) Genomic consequences of traumatic brain injury. In: Neurobiology of central nervous system trauma (Salzman SK, Faden AI, eds), in press. Oxford: Oxford UP.

Collingridge GL, Kehl SJ, McLennan H (1984) The action of some analogues of the excitatory amino acids in the dentate gyrus of the rat. Can J Physiol Pharmacol 62:424-429.

Dash PK, Hochner B, Kandel ER (1990) Injection of the CAMP. responsive element into the nucleus of Aplysia sensory neurons blocks long-term facilitation. Nature 345:718-721.

D'Costa A, Breese CR, Boyd RL, Booze RM, Sonntag WE (1991) Attenuation of Fos-like immunoreactivity induced by a single electroconvulsive shock in brains of aging mice. Brain Res 567:204-211.

de Toledo-Morrell L, Morrell F (1985) Electrophysiological marker of aging and memory loss in rat. Ann NY Acad Sci 444:296-311.

Deadwyler SA, Dunwiddie T, Lynch G (1987) A critical level of protein synthesis is required for long-term potentiation. Synapse 1:90 95.

Douglas RM, Goddard GV (1975) Long-term potentiation of the perforant path-granule cell synapse in the rat hippocampus. Brain Res $86: 205-215$

Douglas RM, Goddard GV, Riives M (1982) Inhibitory modulation of long-term potentiation: evidence for a postsynaptic locus of control Brain Res 240:259-272.

Douglas RM, Dragunow M, Robertson HA (1988) High-frequency discharge of dentate granule cells, but not long-term potentiation, induced c-fos protein. Mol Brain Res 4:259-262.

Dragnunow M, Abraham WC, Goulding M, Mason SE, Robertson HA, Faull RLM (1989) Long-term potentiation and the induction of $c$-fos mRNA and proteins in the dentate gyrus of unanesthetized rats. Neurosci Lett 101:274-280.

Dragunow M, Goulding M, Faull RLM, Ralph R, Mee E, Frith R (1990) Induction of c-fos $\mathrm{mRNA}$ and protein in neurons and glia after traumatic brain injury: pharmacological characterization. Exp Neurol 107: 236-248.

Gallagher M, Pelleymounter MA (1988) Spatial learning deficits in old rats: a model for memory decline in the aged. Neurobiol Aging $9: 549-556$.
Goelet P, Castellucci VF, Schacher S, Kandel ER (1986) The long and the short of long-term memory-a molecular framework. Nature 322 : $419-422$.

Goldowitz D, White WF, Steward O, Lynch G, Cotman C (1975) Anatomical evidence for a projection from the entorhinal cortex to the contralateral dentate gyrus of the rat. Exp Neurol 47:433-441.

Greenberg ME, Ziff L (1984) Stimulation of 3T3 cells induces transcription of the c-fos protooncogene. Nature 331:433-437.

Greenberg ME, Ziff EB, Greene LA (1986) Stimulation of neuronal acetylcholine receptors induces rapid gene transcription. Science 234: 80-83.

Hazel TG, Nathans D, Lau LF (1988) A gene induced by serum growth factors encodes a member of the steroid and thyroid hormone receptor superfamily. Proc Natl Acad Sci USA 85:8444-8448.

Hjorth-Simonsen A, Jeune B (1972) Origin and termination of the hippocampal perforant path in the rat studied by silver impregnation. J Comp Neurol 144:215-232.

Hunt SP, Pini A, Evan G (1987) Induction of c-fos-likc protcin in spinal cord neurons following sensory stimulation. Nature 328:632634.

Jeffery KJ, Abraham WC, Dragunow M, Mason SE (1990) Induction of Fos-like immunoreactivity and the maintenance of long-term potentiation in the dentate gyrus of unanesthetized rats. Mol Brain Res $8: 267-274$

Korol DL, Abel TW, Church LT, Barnes CA, McNaughton BL (1993) Hippocampal synaptic enhancement and spatial learning in the Morris swim task. Hippocampus 3:127-132.

Krukoff TL, Morton TL, Harris KH, Jhamandas JH (1992) Expression of c-fos protein in rat brain elicited by electrical stimulation of the pontine parabrachial nucleus. J Neurosci 12:3582-3590.

Lau LF, Nathans D (1991) The hormonal control regulation of gene transcription. In: Molecular aspects of cell regulation (Cohen P, Foulkes JG, eds), pp 257-293. Amsterdam: Elsevier.

Mack KJ, Mack PA (1992) Induction of transcription factors in somatosensory cortex after tactile stimulation. Brain Res 12:141-147.

Mack KJ, Cortner J, Mack P, Farnham PJ (1992) krox 20 messenger RNA and protein expression in the adult central nervous system. Brain Res 14:117-123.

McNaughton BL, Douglas RM, Goddard GV (1978) Synaptic enhancement in fascia dentata: cooperativity among coactive afferents. Brain Res 157:277-293.

McNaughton BL, Barnes CA, Rao G, Baldwin J, Rasmussen M (1986) Long-term enhancement of hippocampal synaptic transmission and the acquisition of spatial information. J Neurosci 6:563-571.

McNaughton BL, Barnes CA, Meltzer J, Sutherland RJ (1989) Hippocampal granule cells are necessary for normal spatial learning but not for spatially-selective pyramidal cell discharge. Exp Brain Res 76: 485-496.

Mello CV, Vicario DS, Clayton DF (1992) Song presentation induces gene expression in the songbird forebrain. Proc Natl Acad Sci USA 89:6818-6822

Morgan JI, Cohen DR, Hempstead JL, Curran T (1987) Mapping patterns of c-fos expression in the central nervous system after seizure. Science 237:192-197.

Morris RGM (1981) Spatial localization does not require the presence of local cues. Learn Motiv 12:239-261.

Nakabeppu Y, Nathans D (1991) A naturally occurring truncated form of Fos $B$ that inhibits Fos/Jun transcriptional activity. Cell 64:751759.

Nikolaev E, Kaminska B, Tischmeyer W, Matthies H, Kaczmarek L (1992) Induction of expression of genes encoding transcription factors in the rat brain elicited by behavioral training. Brain Res Bull $28: 479-484$.

Paxinos G, Watson C (1986) The rat brain in stereotaxic coordinates, $2 d$ ed. Sydney: Academic.

Reed GD, Robinson GB (1991) Effect of MK801 on long-term potentiation in the hippocampal dentate gyrus of the unanesthetized rabbit. Ann NY Acad Sci 627:381-384.

Richardson CL, Tate WP, Mason SE, Lawlor PA, Draganow M, Abraham WC (1992) Correlation between the induction of an immediate early gene, zif 268 , and long-term potentiation in the dentate gyrus. Brain Res 580:147-154.

Rusak B, Robertson HA, Wisden W, Hunt SP (1990) Light pulses that shift rhythms inducc genc cxpression in the suprachiasmatic nuclcus. Science 248:1237-1240.

Saffen DW, Cole AJ, Worley PF, Christy BA, Ryder K, Baraban JM 
(1988) Convulsant-induced increase in transcription factor messenger RNAs in rat brain. Proc Natl Acad Sci USA 85:7795-7799.

Schreiber SS, Maren S, Tocco G, Shors TJ, Thompson RF (1991) A negative correlation between the induction of long-term potentiation and activation of immediate early genes. Mol Brain Res 11:89-91.

Sheng M, Greenberg ME (1990) The regulation and function of c-fos and other immediate early genes in the nervous system. Neuron 4:477485.

Tischmeyer W, Kaczmarek L, Strauss M, Jork R, Matthies H (1990) Accumulation of $\mathrm{c}$-fos $\mathrm{mRNA}$ in rat hippocampus during acquisition of a brightness discrimination. Behav Neural Biol 54:165-171.

Watson MA, Milbrandt J (1989) The NGFI-B gene, a transcriptionally inducible member of the steroid receptor gene superfamily: genomic structure and expression in rat brain after seizure induction. Mol Cell Biol 9:4213-4219.
Wisden W, Errington ML, Williams S, Dunnetı SB, Waters C, Hitchcock D, Evan G, Bliss TVP, Hunt SP (1990) Differential expression of immediate early genes in the hippocampus and spinal cord. Neuron 4:603-614

Worley PF, Cole AJ, Murphy TM, Christy BA, Nakabeppu Y, Baraban JM (1990) Synaptic regulation of immediate early genes in brain. Cold Spring Harbor Symp Quant Biol 54:213-223.

Worley PF, Christy BA, Nakabeppu Y, Bhat RV, Cole AJ, Baraban JM (1991) Constitutive expression of zif 268 in neocortex is regulated by synaptic activity. Proc Natl Acad Sci USA 88:5106-5110.

Worley PF, Bhat RV, Baraban JM, Stevenson GD, McNaughton BL, Rao G, Barnes CA (1992) Synaptic activation of transcription factors: dissociation of stimulus repetition and LTE in hippocampus of awake behaving rats. Soc Neurosci Abstr 18:1215. 